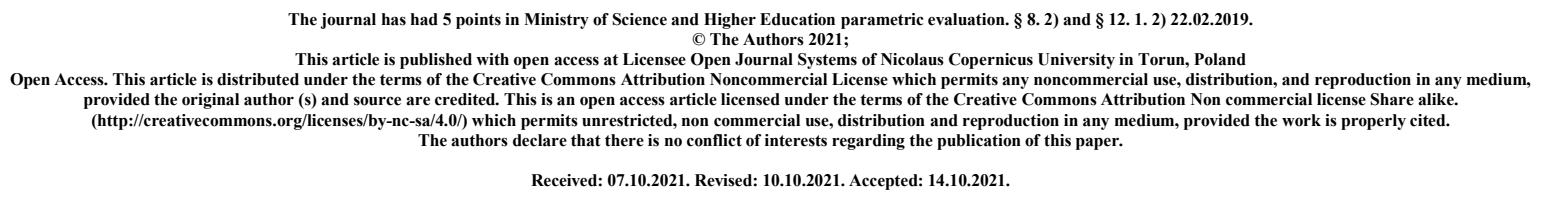

\title{
Children's feelings and attitude towards medical contacts
}

\author{
Bartosz Wojtera ${ }^{1}$
}

ORCID: 0000-0003-4677-0783

e-mail: bartosz.wojtera96@gmail.com

\section{Agnieszka Bugaj ${ }^{1}$}

ORCID: 0000-0001-8259-5551

e-mail: aggsworowska@gmail.com

\section{Joanna Jackowska ${ }^{2}$}

ORCID: 0000-0002-5189-5823

e-mail: drjackowska@gmail.com

${ }^{1}$ Students Research Group at the Department of Otolaryngology, Head and Neck Surgery Poznań University of Medical Sciences, ul. Przybyszewskiego 49, 60-355, Poznań, Poland

${ }^{2}$ Department of Otolaryngology, Head and Neck Surgery Poznań University of Medical Sciences, ul. Przybyszewskiego 49, 60-355, Poznań, Poland

\footnotetext{
Abstract

Introduction and purpose

Medical procedures can be physically harmful and cause psychological trauma among young children, possibly resulting in certain lifelong aversion. The aim of the study was to evaluate children's feelings while undergoing minor medical procedures depending on age, gender and previous experience and to compare it with university students.

Material and methods

We conducted a survey among 382 primary school children, as well as 334 university students. Questions concerned the frame of mind at the moment of examination, during dentist and general physician appointment, vaccination, hospitalization and condition of sore throat.

Results

The experience of hospital stay resulted in better feelings about possible future hospitalization in both groups, and about dentist appointment in the group of children. Girls and women declared lower mood during general physician appointment. Interestingly, in the group of
} 
children boys felt worse at the moment of survey, while in the group of students women felt so. The current frame of mind correlated with an appraisal of all other situations among students, whereas only with physician appointment and vaccination among children. All of above were statistically significant. For both groups, the most unpleasant condition was sore throat. However, in regards to medical procedures exclusively, vaccination appeared to be the most traumatic for children and hospitalization for students.

\section{Conclusion}

Earlier experience and gender of children can affect their feelings about medical procedures. Presented analysis suggests that every medical should do their best to provide pleasant atmosphere for every child during medical contacts.

Key words: Children's feelings; children's attitude; medical contacts; minor medical procedures; pediatric hospitalization

\section{Introduction}

Necessity of hospitalization and related procedures affects emotional and psychological spheres. Especially pediatric patients struggle with inconvenience related with unwanted, but unavoidable healthcare contacts. Unfamiliar medical environment in connection with uncertain and unpredictable sequences and possible physical pain cause children to feel anxious, stressed, confused or even threatened. ${ }^{1-3}$ It is important to provide child-friendly medical care, because it might affect future attitude toward medical procedures. In consequence, individuals might encounter emotional, psychological or behavioral troubles and avoid medical institutions in their adult life. ${ }^{4-6}$

Children might develop significant medical-related trauma on every developmental level, from infancy to adolescence. They need an individualized approach based on their actual developmental stage, which is often not equal to their chronological age. The earlier medical apprehension appear, the more likely it affects children attitude. ${ }^{4,7}$ On the other hand, children might experience positive emotions resulting from medical related contacts. ${ }^{8}$

Various methods of managing with children stress have been investigated including for instance therapeutic play, education about upcoming procedures, a trip around hospital to get familiar with its surrounding, involving in pleasant virtual environment, watching animated films and many other techniques. ${ }^{9-18}$ Typically, parental presence is the essential element of children support, but not all parents are able to reduce stress effectively. ${ }^{10,19,20}$ Children need certain information, understanding and proper sensitivity to cope with process of diagnostics or treatment. ${ }^{21-23}$

Many studies concerned the impact of medical procedures on children's emotions. . $^{1,2,8,10,21,24}$ Generally, they concentrated on interviewing the children in detail, which is definitely a big value. However, most of them regarded limited population.

To our knowledge any study before has paid attention on assessing simple trends of pediatric patients frame of mind related with medical procedures by examining large population and using simple ordinal scale. 


\section{Purpose}

The current study aimed to evaluate children's mood during routine contacts with medical professionals, such as dentists, nurses, hospital personnel and general physician and to compare it with exemplary population of college students.

\section{Material and methods}

Members of Students Research Group at the Department of Otolaryngology, Head and Neck Surgery conducted the questionnaire survey among primary school children during annual otitis media prophylactic screening examination in Kołobrzeg (Poland) in September 2019, organised by Department of Otolaryngology, Head and Neck Surgery from Poznan University of Medical Sciences in cooperation with local authorities.

The children from 14 schools, aged from four to ten, were asked about their feelings at that moment, as well as during: dentist and physician appointment, vaccination, hospitalization and condition of a sore throat. Questions about the mood during examination and the condition of sore throat were the control queries to assess the reliability of responds. We used the simple scale based on six emoticons to evaluate children's mood in each situation. Afterwards, members of Students Research Group examined the presence of palatine tonsils and noted whether the child participant stated being hospitalized.

In the next step, we carried out the Internet questionnaire survey within a group of college students, using the same questions with 6 descriptive phrases as answers. The only modification was that we asked the students whether they had undergone tonsillectomy or not instead of pharynx examination.

We transferred obtained results into six-grade ordinal scale numbered: zero, two, four, six, eight, ten; where zero meant the best frame of mind, and 10 meant the worst frame of mind. Finally, we performed statistical analysis of harvested data in STATISTICA 2012, using Mann-Whitney U Test, Wilcoxon signed-rank test and Spearman's rank-order correlation.

Basic characteristic of studied groups available in Table 1.

Table 1.

Basic characteristic of studied populations.

\begin{tabular}{lcc}
\hline & Group of children & Group of college students \\
\hline Number & 382 & 334 \\
Age & 4 & 18 \\
Minimum & 10 & 27 \\
Maximum & 7 & 23 \\
Median & $6,7 \pm 1,1$ & $22,4 \pm 1,8$ \\
Average & & 239 \\
Gender & 172 & 95 \\
Female & 211 & \\
Male & & \\
\hline
\end{tabular}

The study was conducted in accordance with the Declaration of Helsinki. We omitted the Ethic Commission evaluation, because our study was based on questionnaire survey. It was 
related with no intervention, no invasive tests and collecting no personal data, except age and gender. Nevertheless, every child delivered parental consent for examination and was given opportunity not to undergo the survey depending on the will. Adult students answered the survey voluntarily via the Internet. Qualified research worker physician supervised every stage of the study.

\section{Results}

\section{Primary school children}

Children with history of hospitalization reported better frame of mind during the potential hospital stay $(p<0.001)$ and dentist appointment $(p=0.014)$ than those who had not experienced it before. During performing the survey girls tended to feel better $(p=0.033)$, however, boys stated feeling more comfortable during physician appointment $(p=0.006)$ and condition of sore throat $(\mathrm{p}=0.007)$. Moreover, worse frame of mind during the survey correlated with lower rating of mood during vaccination $(\mathrm{p}=0.013)$ and physician appointment $(\mathrm{p}=0.009)$, as well as younger age correlated with better feeling during survey $(\mathrm{p}=0,027)$. Physician appointment turned out to be the most friendly, whereas the condition of sore throat - the most unpleasant - Table 2. Children appraised dentist appointment as more traumatic than physician appointment $(\mathrm{p}<0.001)$.

Table 2.

Comparison of frame of mind appraisal depending on examined group and situation.

\begin{tabular}{lccc}
\hline \multicolumn{1}{c}{ Examined situation } & Group of children & $\begin{array}{c}\text { Group of college } \\
\text { students }\end{array}$ & $\mathrm{P}^{*}$ \\
\hline $\begin{array}{l}\text { Frame of mind during } \\
\text { the survey }\end{array}$ & 0,98 & 1,69 & $<0.001$ \\
Dentist appointment & 3,85 & 3,20 & $<0.001$ \\
Vaccination & 5,54 & 2,14 & $<0.001$ \\
Hospitalization & 4,01 & 5,05 & $<0.001$ \\
Physician appointment & 2,28 & 2,95 & $<0.001$ \\
Condition of sore throat & 5,79 & 6,43 & $<0.001$ \\
\hline
\end{tabular}

0 - the best frame of mind, 10 - the worst frame of mind

* Wilcoxon signed-rank test

The place of residence impacted the appraisal - children from rural areas stated feeling worse during physician appointment $(\mathrm{p}=0,012)$ and the condition of sore throat $(\mathrm{p}=0,026)$ than children living in cities and towns.

Thirty four children $(8,9 \%)$ marked the happiest face in five or six questions (of total six). These results seem unreliable, therefore, we removed them from statistical analysis.

Almost $47 \%$ of children stated that they had been hospitalized, while 9,4\% had underwent tonsillectomy - Table 3 . It is particularly worrying that $8,6 \%$ of children had never attended the dentist - Table 4. 


\section{Table 3.}

Hospitalization and tonsillectomy rate.

\begin{tabular}{llclc}
\hline & \multicolumn{2}{c}{ Group of children } & \multicolumn{2}{c}{ Group of students } \\
& $\mathrm{n}$ & $\%$ & $\mathrm{n}$ & $\%$ \\
\hline Experience hospitalization & & & & \\
$\quad$ Yes & 179 & 46,9 & 241 & 72,2 \\
Do not know & 25 & 6,5 & 2 & 0,6 \\
Tonsillectomy & & & & \\
Yes & 36 & 9,4 & 69 & 20,7 \\
Troubles in examination/Do not know & 25 & 6,5 & 3 & 0,9 \\
\hline
\end{tabular}

Table 4.

Percent of children who have never experienced dentist appointment depending on age.

\begin{tabular}{cc}
\hline Age & Percent of children \\
\hline 5 & $21,8 \%$ \\
6 & $8,6 \%$ \\
7 & $7,3 \%$ \\
8 & $3,6 \%$ \\
$\geq 9$ & $0 \%$ \\
\hline
\end{tabular}

Fourth to sixth year medicine students had doubts about assessing presence of palatine tonsils in $6,5 \%$ of cases.

\section{College students}

Students with the history of hospitalization reported better appraisal of frame of mind in case of possible future hospital stay $(\mathrm{p}=0,033)$. Men tended to feel better than women at the time of performing survey $(\mathrm{p}=0.031)$ and stated feeling more comfortable during physician appointment $(\mathrm{p}=0.011)$. Worse frame of mind during the survey correlated with lower rating of mood during all of examined situations $(\mathrm{p}<0.05)$. Vaccination turned out to be the most friendly, whereas the condition of sore throat - the most unpleasant - Table 2. We found no statistically significant difference between appraisal of dentist and physician appointment $(\mathrm{p}=$ $0.16)$.

Even $72,2 \%$ of college students stated that they had been hospitalized, while $20,7 \%$ added that they had underwent tonsillectomy - Table 3 . However, $0,6 \%$ of college students have no knowledge if they were hospitalized and $0,9 \%$ have no knowledge if they underwent tonsillectomy - Table 3.

\section{Comparing the groups}

Children's and students' appraisal of frame of mind differed significantly in all analyzed situations - Table 2. 


\section{Discussion}

At first, we considered the effect of previous tonsillectomy on children's reception of medical procedures, but the results showed only one connection. Tonsillectomy affected positively the children's view on future hospitalization, which is identical with earlier hospitalization itself - and unable assessing primary relationship.

Differences within boys and girls may result from their various perception, as well as from possible diversity of treating them by adults, depending on gender.

Surprisingly, we found correlation between age and children's mood only in aspect of feeling during the survey. Primary school children, regardless of age (4-10), had similar attitude toward other examined situations.

Interestingly, both children and students seem to complain more about the clinical condition of sore throat than particular medical contacts. It may suggests that physical pain intrudes human more than possibly unpleasant health-related interventions - which is worth further investigation.

Hospitalization generally showed the same impact. We think that children, who had experienced the hospital stay before, become more familiar with medical environment and feel less stressed in similar circumstances in the future. However, vaccination - as the most traumatic procedure - and physician appointment - as the least stressful - do not follow this trend.

We accidentally found that in many cases, parents decide to make first dentist's appointment of their children too late, which could result in worse oral hygiene and health in the future ${ }^{25}$ Table 3.

We admit that our study is not without limitations. We used general terms in creating the survey and made it brief for better understanding and cooperation with children - broad questions might caused less specific results. Some children might have misunderstood the conception of the survey and treat is as a kind of play - actually, $8,9 \%$ of them marked only the happiest faces. Some students might have stated unreliable responses, because of the Internet questionnaire survey form and their possible lack of interest in detailed evaluation of their attitude. We also found a significant impact of current mood on appraisal of examined situations, especially in the group of students. Furthermore, this group was characterized by a significant gender disproportion in favor of female students.

Our study focuses on children's feelings. Johanna Shapiro et al. examined the creative projects of medical students, concluding that they mostly investigate emotional aspect ${ }^{26}$. Our work definitely proves it. We believe that concentration on patient's feelings and the quality of life should stay in the medical students minds and persist for the future career.

\section{Conclusion}

Earlier experience and gender of children can affect their feelings about medical procedures. Presented analysis suggests that pediatric medical staff should do their best to provide pleasant atmosphere for every child during medical contact. All professionals have to develop their soft skills to improve psychological aspects of pediatric healthcare using and evolving many proposed protocols - with a great emphasis on proper communication, information and education.

\section{Acknowledgements}

We would like to acknowledge the following members of Students Research Group at the Department of Otolaryngology, Head and Neck Surgery for vast, invaluable help with 
collecting surveys among examined children: Marta Łukomska, Aleksandra Nowak, Justyna Palutkiewicz, Matylda Siembab, Julia Sworowska, Mateusz Zając, Szymon Zakrzewski.

\section{References}

1. Salmela, M., Aronen, E. T. \& Salanterä, S. The experience of hospital-related fears of 4to 6-year-old children: Children and hospital-related fears.

Child Care Health Dev 37, 719-726 (2011).

2. Carney, T. et al. Children's Views of Hospitalization: An Exploratory Study of Data Collection. J Child Health Care 7, 27-40 (2003).

3. Donnelly, M. \& Kilkelly, U. Participation in Healthcare: the Views and Experiences of Children and Young People. Int J Child Rights 19, 107-125 (2011).

4. Lerwick, J. L. Psychosocial implications of pediatric surgical hospitalization. Semin. Pediatr. Surg. 22, 129-133 (2013).

5. Lavigne, J. V., Schulein, M. J. \& Hahn, Y. S. Psychological aspects of painful medical conditions in children. I. Developmental aspects and assessment. Pain 27, 133-146 (1986).

6. Duff, A. J. A., Gaskell, S. L., Jacobs, K. \& Houghton, J. M. Management of distressing procedures in children and young people: time to adhere to the guidelines. Arch Dis Child 97, $1-4$ (2012).

7. Ainsworth, M. S. \& Bowlby, J. An ethological approach to personality development. Am Psychol 46, 333-341 (1991).

8. Corsano, P. et al. Speaking about emotional events in hospital: The role of health-care professionals in children emotional experiences. J Child Health Care 19, 84-92 (2015).

9. Topan, A. \& Sahin, O. O. Evaluation of efficiency of puppet show in decreasing fears of school-age children against medical procedures in Zonguldak (Turkey). J Pak Med Assoc 69, 817-822 (2019).

10. Karlsson, K., Dalheim Englund, A.-C., Enskär, K., Nyström, M. \& Rydström, I. Experiencing Support During Needle-Related Medical Procedures: A Hermeneutic Study With Young Children (3-7Years). J Pediatr Nurs 31, 667-677 (2016).

11. Eijlers, R. et al. Virtual reality exposure before elective day care surgery to reduce anxiety and pain in children: A randomised controlled trial. Eur J Anaesthesiol 36, 728-737 (2019).

12. Li, H. C. W. \& Lopez, V. Effectiveness and Appropriateness of Therapeutic Play Intervention in Preparing Children for Surgery: A Randomized Controlled Trial Study. J Spec Pediatr Nurs 13, 63-73 (2008).

13. Yoo, H., Kim, S., Hur, H.-K. \& Kim, H.-S. The effects of an animation distraction intervention on pain response of preschool children during venipuncture. Appl Nurs Res 24, 94-100 (2011).

14. Inal, S. \& Kelleci, M. Distracting children during blood draw: Looking through distraction cards is effective in pain relief of children during blood draw: Distraction is effective on pain relief. Int J Nurs Pract 18, 210-219 (2012).

15. Birnie, K. A., Noel, M., Chambers, C. T., Uman, L. S. \& Parker, J. A. Psychological interventions for needle-related procedural pain and distress in children and adolescents. Cochrane Database Syst Rev (2018) doi:10.1002/14651858.CD005179.pub4. 
16. Yun, O. B., Kim, S.-J. \& Jung, D. Effects of a Clown-Nurse Educational Intervention on the Reduction of Postoperative Anxiety and Pain Among Preschool Children and Their Accompanying Parents in South Korea. J Pediatr Nurs 30, e89-e99 (2015).

17. Tunney, A. M. \& Boore, J. The effectiveness of a storybook in lessening anxiety in children undergoing tonsillectomy and adenoidectomy in northern ireland. Issues Compr Pediatr Nurs 36, 319-335 (2013).

18. Szeszak, S. et al. Animated educational video to prepare children for MRI without sedation: evaluation of the appeal and value. Pediatr Radiol 46, 1744-1750 (2016).

19. Piira, T., Sugiura, T., Champion, G. D., Donnelly, N. \& Cole, A. S. J. The role of parental presence in the context of children's medical procedures: a systematic review. Child Care Health Dev 31, 233-243 (2005).

20. Bauchner, H., Vinci, R. \& May, A. Teaching parents how to comfort their children during common medical procedures. Arch. Dis. Child. 70, 548-550 (1994).

21. Bray, L., Appleton, V. \& Sharpe, A. The information needs of children having clinical procedures in hospital: Will it hurt? Will I feel scared? What can I do to stay calm? Child Care Health Dev 45, 737-743 (2019).

22. Karlsson, K., Rydström, I., Enskär, K. \& Dalheim Englund, A.-C. Nurses' perspectives on supporting children during needle-related medical procedures. Int J Qual Stud Health Wellbeing 9, 23063 (2014).

23. Smith, L. \& Callery, P. Children's accounts of their preoperative information needs. $J$ Clin Nurs 14, 230-238 (2005).

24. Lindeke, L., Nakai, M. \& Johnson, L. Capturing Children??s Voices for Quality Improvement: MCN, MCN Am J Matern Child Nurs 31, 290???295 (2006).

25. Sanguida, A. et al. Age and Reasons for First Dental Visit and Knowledge and Attitude of Parents Toward Dental Procedures for Puducherry Children Aged 0-9 years. J Pharm Bioallied Sci 11, S413-S419 (2019).

26. Shapiro, J., Ortiz, D., Ree, Y. Y. \& Sarwar, M. Medical students' creative projects on a third year pediatrics clerkship: a qualitative analysis of patient-centeredness and emotional connection. BMC Med Educ 16, 93 (2016). 